\title{
Staying Out of the Closet: LGBT Older Adults' Hopes and Fears in Considering End-of-Life*
}

\author{
Kimberley Wilson, ${ }^{1}$ Katherine Kortes-Miller, ${ }^{2,3}$ and Arne Stinchcombe ${ }^{4,5}$
}

\begin{abstract}
RÉSUMÉ
Le vieillissement de la population canadienne et l'hétérogéneité des aînés amène une diversité accrue en fin de vie. L'objectif de cette étude était d'aider à combler les lacunes présentes dans la recherche du vieillissement et la fin de vie des personnes LGBT. À l'aide des groupes de discussion, nous avons tenté de mieux comprendre les expériences vécues des individus LGBT plus âgés, afin de mettre en évidence leurs inquiétudes associés aux dernières phases de la vie. Notre analyse démontre que l'identité LGBT est déterminante lorsqu'on considère le vieillissement et les soins en fin de vie. En particulier, l'identité de genre et l'orientation sexuelle sont des facteurs importants par rapport aux liens sociaux, influençant les attentes des individus envers les soins qu'ils reçoivent, à la crainte unique associée à la révélation de son homosexualité et le maintien de l'identité tout au long du vieillissement et des dernières phases de la vie. Cette étude souligne le besoin de considérer l'identité du genre et l'orientation sexuelle en fin de vie. En particulier, la reconnaissance de l'intersectionnalité et des lieux sociaux est essentielle afin de faciliter des expériences positives par rapport au vieillissement et des soins en fin de vie.
\end{abstract}

\begin{abstract}
Canada is experiencing population aging, and given the heterogeneity of older adults, there is increasing diversity in late life. The purpose of this study was to help fill the research gaps on LGBT aging and end-of-life. Through focus groups, we sought to better understand the lived experience of older LGBT individuals and to examine their concerns associated with end-of-life. Our analysis highlights the idea that identifying as LGBT matters when it comes to aging and end-of-life care. In particular, gender identity and sexual orientation matter when it comes to social connections, in the expectations individuals have for their own care, and in the unique fear related to staying out of the closet and maintaining identity throughout aging and end-of-life. This study underscores the need to consider gender identity and sexual orientation at end-of-life. In particular, recognition of intersectionality and social locations is crucial to facilitating positive aging experiences and end-of-life care.
\end{abstract}

1 Department of Family Relations and Applied Nutrition, University of Guelph

2 School of Social Work, Lakehead University

3 Centre for Education and Research on Aging and Health (CERAH), Lakehead University

4 School of Psychology, University of Ottawa

5 Faculty of Human Sciences, Saint Paul University (Ottawa)

* The authors acknowledge the Law Commission of Ontario who provided funding for this project. We also thank our community partners who supported our recruitment. Finally, the authors thank the older LGBT individuals who took the time to participate in focus groups across Ontario and share their experiences with us.

Manuscript received: / manuscrit reçu : 01/09/16

Manuscript accepted: / manuscrit accepté : 27/05/17

Mots-clés : vieillissement, fin de vie, LGBT, lesbienne, gai, transgenre

Keywords: aging, end-of-life, LGBT, lesbian, gay, transgender

Correspondence and requests for reprints should be sent to / La correspondance et les demandes de tirés-à-part doivent être adresées à :

Kimberley Wilson, PhD, MSW

Assistant Professor, Adult Development \& Aging

Department of Family Relations and Applied Nutrition

University of Guelph

50 Stone Road East

Guelph, ON N1G 2W1

$<$ kim.wilson@uoguelph.ca> 
You've created spaces for yourself where you're comfortable, then suddenly ... somebody is gonna put you in the closet. I don't wanna live in a closet, I don't need to live in a closet, I'm not interested in a closet... (Focus Group Participant)

Despite recent legislative action to grant equal rights to LGBT individuals (e.g., the Civil Marriage Act), health research, health education, and health care landscapes in Canada have not fully accounted for the unique health needs of LGBT older adults. Within Canada's aging population, there is significant heterogeneity, not only in terms of age but also regarding other social determinants and social locations. Sexual orientation and gender identity are key determinants of health, particularly when it comes to discrimination and social inclusion (Ontario Ministry of Health and LongTerm Care, 2012). The intersection of age and gender identity/sexual orientation is an important consideration given the potential for the layering of ageism with discrimination.

Many gay, bisexual, and transgender (LGBT) communities, and older adults who identify as LGBT, have experienced discrimination (Averett, Yoon, \& Jenkins, 2011; Haber, 2009; Kimmel, 2014). Negative consequences of such acts of discrimination and homophobia include detrimental psychosocial well-being (Haber, 2009) and barriers to care for older LGBT adults within health systems (Brotman, Ryan, \& Cormier, 2003). There remains, however, a paucity of Canadian literature on the experience of LGBT aging, particularly in the area of end-of-life (Stinchcombe, Smallbone, Wilson, \& Kortes-Miller, 2017).

Older adults share many hopes and fears at the end-oflife, but LGBT older adults have unique needs, which research has helped to elucidate. For example, LGBT individuals more often prefer the presence of nonbiological social support during end-of-life, compared to preferences of their heterosexual peers (MetLife Mature Market Institute \& the Lesbian and Gay Aging Issues Network of the American Society on Aging, 2010), and may prefer a close friend to have legal rights for end-of-life decisions rather than a family member (Arthur, 2015). Furthermore, feelings of disenfranchisement, isolation, and anxieties of being discriminated against due to sexuality have been identified in previous research as negative emotions that older LGBT adults may experience as they near end-of-life (Arthur, 2015; Brotman et al., 2007; Kimmel, 2014). Older LGBT adults have also expressed fear about receiving care within institutionalized settings, such as long-term care (Witten, 2014). In particular, research has identified fears about harassment and discrimination that are directly related to sexual orientation or gender identity by service providers or residents of homes; this perceived discrimination can lead to stress, which decreases the quality of care received (Arthur, 2015). It can also discourage older LGBT persons from accessing long-term care facilities if they believe they will be mistreated (Brotman et al., 2007). Work emerging from Alzheimer's Australia (2014) indicates that some trans older adults would rather take their own lives than risk entering long-term care.

To date, much of the literature in this area highlights the need for increased education for service providers to increase the cultural competency related to LGBT aging and to reduce heteronormativity within health systems (Aldredge \& Conlon, 2012; Arthur, 2015; Griebling, 2016). Education in LGBT cultural competency has been shown to be mutually beneficial between service provider and patient, with work from Porter and Krinsky (2014) indicating that such training can increase the levels of comfort a service provider feels when treating or providing care to an individual who is not heterosexual. Approaches to improving cultural competence among health care providers is a prime endeavour; yet, to truly meet the health care needs of this population it is important to first understand their experiences with the health care system as well as their fears and hopes. Although much of the research on LGBT aging originates from the United States, Australia, and the United Kingdom, their systems and medico-legal contexts are not directly comparable to Canada's, and thus their findings are not necessarily generalizable to Canadian contexts.

Consequently, the purpose of this study was to aid in filling the gaps in current research on LGBT aging and end-of-life. We sought to better understand the lived experience of older LGBT individuals and their caregivers within the health care system in Ontario as well as highlight their concerns associated with the last stages of life.

\section{Methods}

\section{Participants}

Twenty-three LGBT-identified individuals ranging from 57 to 78 years $($ mean $=67.39)$ participated in the study. Using a brief demographic questionnaire, which included open-ended questions to allow for diversity of gender identities and sexual orientations, participants were asked to self-identify. Participants were varied in their responses revealing diversity within gender identities and sexual orientations. In terms of gender, responses included "Male", "Female", "mostly woman but not feminine". In terms of sexual orientation, responses included "lesbian", "gay", "bisexual", "two-spirit lesbian", " ?", and "bisexual to gay". Participants identified their relationship status as "partnered within a chosen family", "single", "partnered", "married", "single, divorced, grandfather", and "partnered 41 years". 
During our discussions, several participants disclosed that they had previously been in long-term heterosexual relationships and had children. In response to a question about living arrangements, participants reported living with a spouse or partner and living alone. Working statuses included "long-term disability", "retired - working part-time", "retired", "active volunteer", "working full-time", and "student". The majority of participants reported having played a caregiver role at some point in their lives. Overall, the majority of participants reported a high level of education ranging from college diplomas to graduate degrees; however, not all participants had completed secondary school. Participants reported living with chronic diseases, including multiple sclerosis, cancer, and HIV, but in general, self-reported health was good.

\section{Procedure}

We conducted three focus groups, one each in urban centres in Northern Ontario, Southern Ontario, and Eastern Ontario, Canada. The aim behind holding focus groups in three locations was to capture the experiences of individuals residing in urban settings with a large and organized LGBT presence as well as those of individuals residing in less-resourced areas with fewer available supports.

The focus groups were composed of between six and nine participants, and each focus group lasted approximately 1.5 hours. The study received approval from the Research and Ethics Board (REB) at the University of Guelph, Ontario. All participants received an information letter and provided informed consent. Participant recruitment occurred with support from community-based LGBT organization/support groups. A number of participants had either formal or informal affiliations with these organizations, but this was not a requirement for participation. Additional recruitment via social media (Facebook and Twitter) and snowball sampling also occurred in order to reach others not connected to support groups. None of the participants withdrew from the study, and participants were reimbursed for costs incurred while participating, such as for travel and parking.

Informed by the life-course theoretical perspective and building on previous research, a semi-structured interview approach was designed to obtain information from participants. The life course theoretical perspective focused on social and historical contexts, the importance of relationships, transitions and timing of transitions, and individual agency (Bengtson, Elder, \& Putney, 2005). The focus group questions were designed to promote open-ended responses that aligned with the tenets of the life course theoretical perspective and built on the researchers' review of the literature. The questions posed to guide the focus group discussion consisted of the following:

1. What kind of things do you consider when you think about the later stages of your life?

2. What rewards do you anticipate?

3. What challenges?

4. What kind of unique needs do older LGBT adults have?

5. Please describe how you use the health care system presently.

6. How would you describe your relationship with your health care providers?

7. What is done well for you?

8. What could be done better?

9. Please describe any barriers you may face preventing you from getting the kind of care you would like.

10. What do you hope for at the end of your life?

11. What fears or concerns do you have?

12. What resources are you aware of for LGBT elders nearing the end of their lives?

13. What policies (social, government, financial) are you aware of that support or hinder LGBT elders nearing the end of their lives?

14. Is there anything else you would like us to know?

15. Would you feel comfortable using video technology to share your personal experience and story?

16. If you had one wish for your end-of-life experience, what would it be?

The focus groups were digitally recorded with the consent of the participants and were transcribed. We then analysed transcripts using an inductive thematic analysis approach (Braun \& Clarke, 2006). After familiarizing ourselves with the data, during the first phase a member of the research team performed an initial scan of the data to begin generating initial codes. In the second phase, members of the research team met to identify themes through collaborative analysis. A constant comparison process was employed to guide coding, categorizing, and theoretical sampling. In the final analysis phase, we reread the data and extracted samples that best illustrated the final themes. Members of the research team reviewed all coding to ensure that there was agreement and accuracy within the coding process and thematic analysis. It was through attention to this process and analysis that four themes emerged, as outlined next.

\section{Results}

The analysis of the transcripts from the three focus groups with older adults identifying as LGBT revealed an overarching theme, three main themes, and six subthemes. Although there was rich data regarding commonalities pertaining to perceptions of end-of-life that apply generally to aging and older adulthood, through our analysis we highlighted contributions that participants made which focused upon their unique needs 
relating to gender identity and sexual orientation. The overarching theme, "identifying as LGBT matters," encompassed the three main component themes: (1) social connections and support, (2) expectations for care, and (3) staying out of the closet (see Figure 1).

Participants in this study grew up during a time when same-sex relationships were often hidden and even considered to be illegal. Some of the participants in this study experienced discrimination or even abuse because of this environment. As a result of these experiences, participants reported having strong concerns about the care they will receive as they near the end of their lives; they know that identifying as LGBT will play an important role in how and where they are cared for. They recognized that being LGBT intrinsically matters to them and is an integral part of who they are. Participants shared how they are fearful that identifying as LGBT will impact their care, access to support and ability to "stay out of the closet", and how they hope to have a good quality of living until the end of their lives. The following themes and associated sub-themes expand on the overarching theme that "identifying as LGBT matters."

\section{Social Connections and Support}

The experiences shared in the focus groups demonstrate that social connections and support are priorities for older adults identifying as LGBT as they near the end of their lives. In our focus groups, participants delineated between familial and support from their social communities. Participants also expressed fears about the breakdown of supports as they grow older, and noted that this fracturing might contribute to the risk for social isolation for LGBT older adults.

\section{Familial Support}

Participants reported seeking support from both biological family members and those not related to them. Some participants shared that some LGBT individuals may be less likely to have children and thus are less likely to have adult children to take care of them as they approach end of life;

I often think ... is the network around me going to be strong enough and be there to support me, cause some ... many of us may end up on our own even if we're in partnerships at the moment... and it's not always clear is there going to be a partner. We're not as connected to family as many cases, as lots of other people would be, not having, many of us, not having any children. So it's a question of is that road going to be a very lonely road, or am I going to have a very supportive network around me that helps me through that final journey.

Although many participants in our focus groups indicated that they had biological children, there were also strong concerns from others expressed about increased risk for social isolation as a result of having no children. As one participant noted;

I don't have children so nobody there is going to take care of me. I have good friends, they're not going to take care of me either; I don't expect them to. So I'm feeling pretty alone. I don't have a partner. I'm pretty alone. And because of that I have been thinking of this a lot.

This participant from the first focus group in Northern Ontario asked:

Who's going to want to look after you? Who's going to want to look after me? Like ... when you

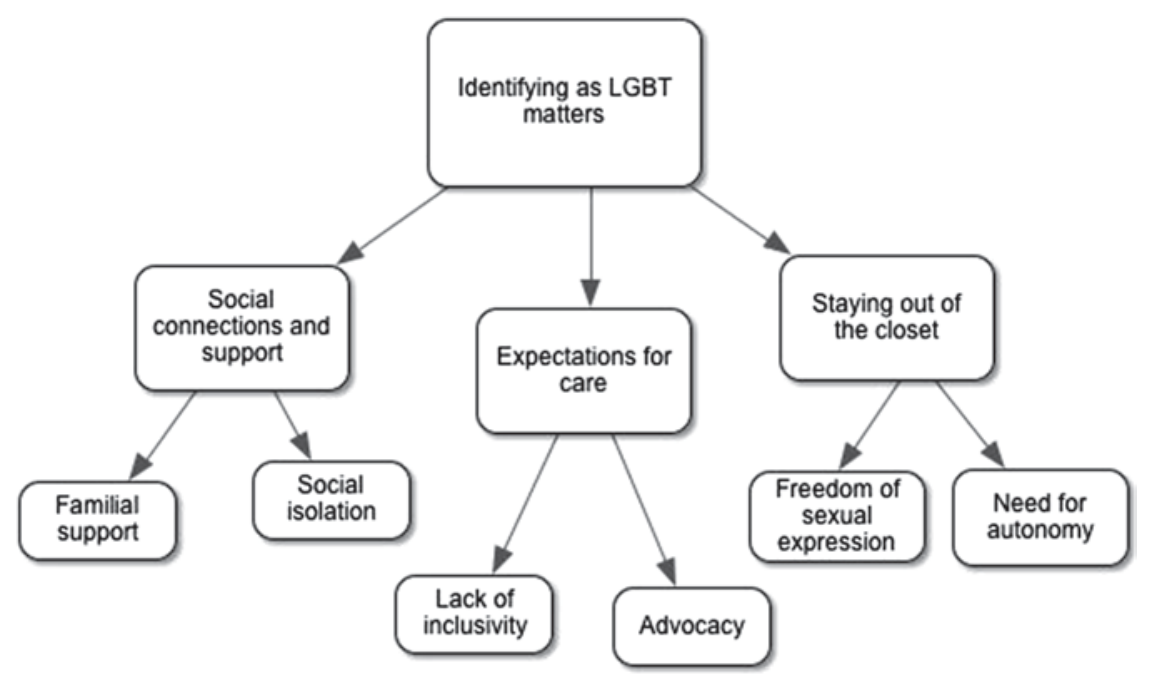

Figure 1: Map of thematic analysis. The overarching theme was "identifying as LGBT matters", which encompassed three main component themes: (1) social connections and support, (2) expectations for care, and (3) staying out of the closet 
think about it, who's going to want to look after me, and who's going to want to look after a gay woman? You know?

\section{Social Isolation}

A second sub-theme of social connections and support was social isolation. In addition to the participants' diversity of family contexts, the participants' historical experiences of stigma and discrimination influenced their perceptions and fears about social isolation. Despite the recent advances in equality in Canada, the historical context is particularly relevant for older LGBT Canadians, as noted by one participant:

We're all just human beings, and many of us have had a lot of pain and loneliness and isolation and secrecy, and it needs to stop and not everybody is aware of that yet.

Anxiety about social isolation was not only expressed about the later stages of life, but also specifically around dying and death. The fears around social isolation and death were exacerbated for some participants who are without partners and without familial connections to advocate for them. This anxiety was expressed by a participant as follows:

When I'm dying I feel like I'm going to die alone. Without any power, so I just avoid that without even thinking about it. I tell my best friend [redacted] to fight for me like crazy. I wrote a will, at least maybe somebody will listen to my will.

Many focus group participants expressed the desire for policies to be more open to the idea of chosen families, which are non-biological family members selected by the individual. While caregiving roles and the risk of social isolation are not unique to LGBT older adults, focus group participants indicated that they are less likely to have spouses to fulfill caregiving requirements, which might have significant ramifications for the receipt of informal care. One participant, self-described as a gay man, questioned if the caregiving journey and the risk of social isolation might be particularly unique for gay men, saying:

\begin{abstract}
... the fact is that women tend to build their circles because of family and that ... easier than men do, and men tend to be competitive and work oriented and that, so when we get to later in life we don't have those natural circles in even using your family as support.
\end{abstract}

Despite this potential difference, participants also reflected on previous examples of success in building supportive networks among the gay community while recognizing barriers, such as ageism, that may influence social supports for older LGBT men:

... gay men are capable of doing this! I ran [a local caregiver program] in the age of AIDS ... but I think there's an issue around gay men. There is ageism [it's] huge in the gay male community, and I think that's very easily internalized.

The theme of social isolation was also discussed in the context of community settings. In particular, participants reflected on the risk of social isolation even within a group setting if they are not able to relate to their peers or feel accepted. Fears about long-term care are discussed in subsequent sections; however, as noted below, social isolation within long-term care was also a concern for participants:

You have to have 3 meals a day with 3 other people. Cause they put 4 people at a table. So, this whole thing about isolation, if you're ... I don't know what scenario to give you. If you go back into the closet in a LTC home, okay you ... what do you talk to these other 3 people about? Because your life has been LGBT, so you're going to pretend you're straight? ... If you're an out-person then the home must be very careful of who they put you with. The homes are constantly reassigning tables, dining room seating. So, that's an important area to consider. How not to have that isolation, but have that acceptance.

\section{Expectations for Care}

Within focus group discussions, participants clearly identified their expectations, hopes, and fears around their care towards the end-of-life. Across locations and different health systems, similar fears around care emerged in discussions. Furthermore, participants identified that they anticipated the need to advocate for themselves in order to receive the level of care they expect.

\section{Advocacy}

Many of the participants in this study shared stories of how they had been advocates for the rights and acceptance of LGBT communities throughout their lives. This advocacy had been an important part of their lives and a vital contribution to their community but now, as they aged, they found themselves more tired and less able to do the advocacy work that they thought is required:

[...] what struck me is unless you have a support circle out there who will get in and advocate and get you services while you're supposed to be under care, you're extremely vulnerable. I just, it ... I've always been a loud advocate, but it comes to a point where you can't advocate for yourself and who's going to do it? And you need that in both hospitals and certainly in nursing homes. And I ... I think the stats are that gay people are more likely, twice as likely, to be living on their own. 
Participants also identified that advocacy was going to be as important in nearing the last phase of life as it had been earlier in their lives. In particular, the need to advocate for individuals who identify as being transgender was thought to be a priority:

And the area I think is going to be the worst and will be the worst is for transgender individuals because you're gonna have workers finding somebody coming in whose physical body doesn't match their gender identity, and I see that as ... a source of horrendous problems ... I mean as it is right now for transgender individuals, life is most difficult.

\section{Lack of Inclusivity}

Fears about homophobia, stigma, and discrimination were also reflected in the significant discussions about the lack of inclusiveness in the health care system as a whole, but particularly within long-term care. Almost universally, participants described the lack of inclusivity as a barrier to receiving quality care at the end-of-life. Religious affiliations of different health care organizations were identified as a contributing factor to a lack of inclusivity in the environment for LGBT residents and their families. Participants discussed their concerns about the fact that many of the long-term care facilities were run by Catholic organizations and how this may impact their care:

\begin{abstract}
Let's put that on the table right now ... I'm very frustrated and angry about faith-based approaches to anything regarding our health. If you choose that and wish that, cool. I'm sure there's many places you can access, but to even consider it or think about being what I would call trapped or prisoned in a faith-based institution makes me nearly apoplectic.
\end{abstract}

In addition to religious affiliation, heteronormative assumptions made by health care providers were a common theme emerging from our participants that affect inclusivity. As shared by a gay male who spoke about his recent experience within a hospital:

And then if they were to ask you, well shall we call your wife? [laughter], then there's a whole other issue there that you got to address.

The experiences of heteronormativity were also reflected in the strong desire shared among all participants to have access to LGBT-friendly care, particularly primary care. Echoing the findings in our literature review, many LGBT older adults cited concerns about access; for our participants this included access to a family physician both in terms of proximity and in terms of LGBT-positive spaces. Participants expressed the value of a physician who either identifies as part of the LGBT community or is a strong ally:
There is a big difference [if] the doctor happens to be gay, I'm telling you, but it is like heaven sent, this man knows the questions, he knows your struggles, and I know that we're not going to find a lot of gay doctors necessarily that identify themselves and do what our doctor does: take only LGBT clients, cause there's so many of us that need that kind of help, you know, even for psychological help.

I guess I also really am concerned about I don't want my doctor to retire before I die because he happens to be good. But he's not the youngest one on the block either, and it's not an easy thought to think in later life finding a new doctor who understands what you've been through or the journey or maybe is even gay positive.

The participants in this study also had expectations that, as they near the final stages of life, their care would also be inclusive of their needs to express their sexuality:

...when people reach the point of needing support or going into long-term care, the lack of support, especially for those of us that are LGBT ... long-term care right now does not have ... doesn't believe in sex, for example, and certainly not in gay, lesbian sex - well, sexuality - there's a severe lack in cultural competency in training for people who are going to be working in long-term care.

Despite their desire for inclusivity and freedom of sexual expression in their care, participants also shared experiences of stigma and discrimination in their health care interactions:

I remember the doctor telling, "I don't deal with people like you, you're HIV+, there's one place that you need to go, and this is it." And I felt alone, depressed, didn't have the resources until I was connected and I went to Dr. [redacted] and the amazing clinic, but to be told that was like heartbreaking. Totally awful.

The experience of stigma and discrimination was not unique to sexual orientation or HIV status. Participants also reflected on the unique challenges of receiving inclusive care for the transgender community:

... some pretty nasty stories about - you know, like trying to deal with the health care system and, you know, people... doctors just oh god... don' $t$ want to deal with that trans-vagina.

A prominent system-level barrier was related to the collection of demographic information, or a lack thereof, which can lead to the "invisibility" of the LGBT population across the lifespan but particularly in late life. One participant reflected that he was told there were no LGBT individuals in a particular seniors' community, and yet as he noted:

Well, they're not being asked. ... I know what the form was for intake and it was not there ... And if it's not then it needs to go on there like any other 
public form like ... how do you identify? But this thing about acceptance is ... when you say we have no gay people here that's the façade, that's the image you're projecting. There are LGBT people in every home, but in the past most of them are in the closet or back in the closet again ...

This gap in demographic information was a concern for multiple participants, with one pointing out that only one Local Health Integration Network (LHIN) in Ontario collected orientation and identity. As one participant eloquently stated:

Failure to collect epidemiological or demographic information is fundamental because they don't ... And so if you don't acknowledge the presence of people, it's difficult to get them rights.

\section{Staying out of the Closet}

The freedom to be open about one's sexual orientation and/or identity and the safety to express it was a salient need acknowledged by the focus group participants. They expressed a fear that this freedom would end if they needed to be institutionalized in the later stages of life and worried that they might be "forced back into the closet". A number of participants conveyed that they would not want to go back into the closet because they had worked so hard for the right and freedom to express their identity and would not want it taken away from them. As one participant unequivocally stated:

...we've all fought for our identity you know? Like tooth and nail and ... I know from my own personal experience that ... Just how transformative it was, fundamentally transformative, every aspect of my life just suddenly realized that I am who I'm supposed to be and honest to god I would rather fucking die than go back. I mean honestly life would not be worth living.

\section{Freedom of Sexual Expression}

Sexuality and sexual expression in late life is already often a taboo topic, particularly within institutionalized care settings. Layering minority status of gender identity and/or sexual expression can further stigmatize LGBT individuals in their freedom of sexual expression. Some participants shared that they believed that hiding one's sexual identity might be necessary in some institutions if older adults who identified as LGBT wanted to receive the same quality of care as their heterosexual counterparts:

There are LGBT people in every home, but in the past most of them are in the closet or back in the closet again. [...] To get into a home of choice are they willing to go into the closet when they don't expect there's going to be a, you know, chance or need for romance?
Some participants shared stories of people they had known who were living in long- term care:

A fellow, he lived on his own far beyond the years that he should have [...] he wound up in a [redacted] home which actually, despite the crucifixes on the wall which would bother me, he got very good care, very good care. But ...this was at the cost of him saying "don't tell anyone I'm gay."

"The closet" represents being hidden for individuals who identify as LGBT. Being in the closet is an expression that is connected to a lack of disclosure of sexual orientation or gender identity, including aspects of sexual identity and sexual behaviour. Being forced back into the closet represents a fear of loss of autonomy, identity, and freedom of sexual expression. Participants expressed fear that they were at risk of being coerced back into the closet towards the end of their lives in order to feel safe during a period in which they anticipated being vulnerable and lacking in power.

\section{Need for Autonomy}

Participants in the focus groups were attuned to systemlevel barriers, and these were reflected in their discussions concerning social isolation, fears and hopes, and advocacy needs. These common threads wove together and highlighted many of the systemic issues in the health and social care system that affect access and utilization among older LGBT older adults, especially in the last stages of life.

One such example included the complexity of the medico-legal frameworks, which can prevent people from enacting their wishes as they age and at the end-of-life:

I would want control. I do want control and I don't think it's going to be very easy to get. .... Getting a DNR [do not resuscitate] piece of paper is extraordinarily difficult to get. The hoops you have to go through - all of those kinds of things. So ... I'm pretty realistic about ...

In short, as the participants put it, if you do not acknowledge the presence of people, it is difficult to guarantee their rights. This invisibility also contributes to the heteronormative concentration within the training, education, policy, and practices of the health care system. Heteronormative assumptions were common, and most participants had personal experience of having providers make improper assumptions about their sexual orientation. As one lesbian participant related:

I had one physician who said - I went up to him not too long ago, couple months ago ... and he said, well your husband should be with you on this matter and I said, I don't have a husband, I'm not interested in having a husband, something like that. 


\section{Discussion}

The purpose of this study was to begin to fill the gaps in current research on LGBT aging and end-of-life in Canada. We sought to better understand the lived experiences of older LGBT individuals and their caregivers within the health care system in Ontario as well as to highlight their hopes and fears surrounding endof-life care. Through our inductive analysis, we developed a thematic map that centred on the idea that identifying as LGBT matters when it comes to aging and end-of-life care. In particular, gender identity and sexual orientation matter when it comes to social connections later in life, in the expectations that individuals have for their own care, and in the unique fear related to staying out of the closet and maintaining identity throughout aging and end-of-life.

These data contribute to the literature and knowledge on LGBT aging and end-of-life, particularly within a Canadian context. Echoing previous research, participants from our study reinforced the idea that sexual orientation and gender identity are key determinants of health. Participants were able to draw on previous life experiences and reflect on instances of discrimination with health care providers. Aligning with the work of Brotman et al. (2006), these experiences created barriers to care, and participants feared their end-of-life experiences might also be affected by their gender identity and/or sexual orientation.

The Public Health Agency of Canada (2013) identified social support networks as a key social determinant. Research has indicated that non-biological social supports are key resources for LGBT individuals as they grow older and when preparing for end-of-life (Arthur, 2015; MetLife Mature Market Institute \& the Lesbian and Gay Aging Issues Network of the American Society on Aging, 2010). Although same-sex partnerships are legally recognized in Ontario, our participants also discussed the need to have non-biological or partner supports while growing older. Other participants, particularly those without partners or children, spoke about their fears concerning social isolation in end-oflife, aligning with previous research. It is important to consider the trajectory of this cohort of older adults when considering the social support networks of LGBT older adults. Future cohorts may have different experiences, given the social and historical context of their life course; however, the baby boom generation (and those older) experienced significant shifts in how the legal system addresses the rights of LGBT individuals, and this may have been a unique feature of aging for this cohort.

Despite the current medico-legal context, participants in our focus groups expressed strong fears about needing institutionalized care, fears that have also been reported elsewhere in the literature (e.g., Alzheimer's Australia, 2014; Arthur, 2015; Witten, 2014). In particular, concerns about religious affiliations of many long-term care providers were a unique finding that emerged from our data. Fear of institutionalization was compounded in the case when care might be provided by an organization linked to a religion and/or religious organization that historically (and/or currently) oppresses and discriminates against sexual and gender minorities. Despite the regional difference in our focus groups, this concern was raised unprompted in all three discussions. Participants almost universally highlighted their fears about having to return to "the closet" in order to receive quality care within longterm care settings and spoke with fear and dread about this possibility.

Although participants actively recognized barriers in the current systems, they also had innovative ideas about how to shift culture, such as creating alliances within long-term care homes and other social environments:

I think the model of GSAs (Gay Straight Alliances) which are now in almost every secondary school could be reconfigured to meet the same needs in long-term care communities or retirement homes, maybe even hospitals or community health organizations. The Alliance, or whatever it could be renamed, would be a representation of residents, especially LGBTQ identified ones, staff members and a board member perhaps. Family members of residents could even be included. They would be helpful and given responsibility in educating and bringing awareness of inclusivity and acceptance in the jurisdiction that they represent.

Canadian public health authorities have emphasized that social environments are key determinants of health and the values and norms of a social environment can influence the well-being of individuals, and therefore the perception (and reality) of norms and values of particular institutions may have particular impacts for LGBT individuals (e.g., Public Health Agency of Canada, 2013).

For clinicians, researchers, and decision makers, when using a social-determinants-of-health lens, it is particularly important to recognize and consider intersections of age, gender identity, and sexual orientation, given that they are non-modifiable determinants. Furthermore, evidence has indicated that these nonmodifiable determinants can influence access to health services (e.g., Ontario Ministry of Health and LongTerm Care, 2012; Wade, Bourgeault, \& Neiterman, 2015). For older LGBT individuals and those preparing for end-of-life, creating social environments and health systems that are inclusive and facilitate quality endof-life care is vital. 
As previously identified in the literature (e.g., Aldredge \& Conlon, 2012; Arthur, 2015; Griebling, 2016), there is a need for education to ensure culturally competent and LGBT-friendly services. These educational initiatives should be widely promoted so that older LGBT adults are aware of the training and cultural shifts within systems that have historically been oppressive. In this vein, our study participants noted how powerful symbols, such as a rainbow flag, can be vital in identifying an organization that is LGBT-friendly.

Borrowing from the literature on reducing stigma associated with mental illness that some have experienced with health care providers, we consider social contact interventions that include the lived experience of LGBT individuals to be a crucial ingredient in reducing stigma (Pietrus, 2013). Thus, older adults who identify as LGBT should be included in future training and educational programs. To reduce participant burden, this could also be achieved through knowledge mobilization tools such as digital stories that focus on the experience of stigma and discrimination as barriers to care. Participants in our focus groups identified their invisibility in health-systems research as resulting from the lack of data collected on sexual orientation and gender identity. This is an important epidemiological gap that must be remedied in the collection of census data, health data, and other research. Furthermore, the use of LGBT-specific policy lenses would ensure that sexual orientation and gender identity are included in practice and policy settings.

\section{Limitations}

Despite the contributions of this work to the research and policy landscapes, there are important limitations to note. Although our participants were diverse in terms of self-identified sexual orientation, they were otherwise a fairly homogenous sample. The trans community was not well represented, a gap seen elsewhere in the literature. Among our 23 participants, there was little ethnic diversity, and participants were generally highly educated. Many of our participants self-identified as being active advocates who were highly engaged and resourced in terms of their knowledge about the health care system. Although many of our participants are well resourced and have knowledge about the health care system and this may be viewed a limitation of our current sample, it is important to note that this highly resourced group still expressed significant concerns and fears about their aging process and end-of-life. We can speculate that more at-risk LGBT individuals would have even greater concerns and needs, thus requiring additional intersectional research in this area. Although we conducted focus groups in three different regions in Ontario, the study did not include rural or remote regions. Accordingly, although this work contributes to the base of Canadian research, it is limited in scope given the Ontario focus. As health care in Canada is provincially administered, it is important to expand this work to other regions to understand the experience of LGBT aging in other provinces and territories.

Another key lesson from this work involved the need to build rapport and trust as relative "outsiders". Within each community, a key to our recruitment strategy was working with community agencies and having a champion who supported our research. In one focus group, we were explicitly questioned about our positionality and commitment to valuing the voices of our LGBT participants. This was an important component of gaining trust within that particular focus group, and as a research team this required reflexivity and debriefing in order to proceed with our research. As a team, we have demonstrated our commitment and research expertise by continuing to partner and advocate with the LGBT communities who supported our research.

\section{Conclusion}

As a nation, Canada is experiencing population aging, resulting in increasing diversity in late life. Although social policy advancements have been made to promote greater equality, individuals growing older who identify as LGBT are one particular group that has remained less visible. This is reflected in epidemiological gaps, research and policy, and clinical care. Advancements in equal human rights and protections have been successfully advocated for and achieved by older adults who identify as LGBT, yet these adults continue to express fears about their care and autonomy at the end of life. Furthermore, despite policy advancements around equal rights related to sexual orientation, gaps remain in the rights related to gender identity. Leveraging learning from previous work, our study has underscored the need to consider gender identity and sexual orientation in older adulthood and at the end-of-life. Recognition of intersectionality and varying social locations is crucial to facilitating positive aging experiences and good end-of-life care. Older LGBT adults have unique needs and expectations when it comes to aging and end-of-life. In particular, fears around staying out of the closet and around institutionalization, coupled with the need for different social support networks, are salient. There is a demographic and moral imperative to respond to the needs of LGBT older adults to ensure inclusive health systems that respond to aging and facilitate good end-of-life experiences. Future work should include the voice of LGBT older adults in education and advocacy initiatives to reduce discrimination, enhance social environments, and ensure that no individual feels a need to return to "the closet" to receive quality care as they grow older and approach end-of-life. 


\section{References}

Aldredge, P. A., \& Conlon, A. (2012). Reflections: Gay men and lesbians at end-of-life. Journal of Social Work in Endof-Life $\mathcal{E}$ Palliative Care, 8(2), 113-118.

Alzheimer's Australia (2014). Dementia, transgender \& intersex people: Do service providers really know what their needs are? Retrieved from https://sa.fightdementia.org. au/sites/default/files/130739_LGBTI\%20Discussion\%20 Paper.2-21.pdf

Arthur, D. P. (2015). Social work practice with LGBT elders at end of life: Developing practice evaluation and clinical skills through a cultural perspective. Journal of Social Work in End-of-Life E Palliative Care, 11(2), 178-201.

Averett, P., Yoon, I., \& Jenkins, C. L. (2011). Older lesbians: Experiences of aging, discrimination and resilience. Journal of Women E Aging, 23(3), 216-232.

Bengtson, V. L., Elder, G. H., \& Putney, N. M. (2005). The lifecourse perspective on ageing: Linked lives, timing and history. In M. Johnson (Ed.), The Cambridge handbook of age and ageing, (pp. 493-501). Cambridge, ENG: Cambridge University Press.

Braun, V., \& Clarke, V. (2006). Using thematic analysis in psychology. Qualitative Research in Psychology, 3(2), 77-101.

Brotman, S., Ryan, B., \& Cormier, R. (2003). The health and social service needs of gay and lesbian elders and their families in Canada. The Gerontologist, 43(2), 192-202.

Brotman, S., Ryan, B., Collins, S., Chamberland, L., Cormier, R., Julien, D., ... Richard, B. (2007). Coming out to care: Caregivers of gay and lesbian seniors in Canada. The Gerontologist, 47(4), 490-503.

Griebling, T. L. (2016). Sexuality and aging: A focus on lesbian, gay, bisexual, and transgender (LGBT) needs in palliative and end of life care. Current Opinion in Supportive and Palliative Care, 10(1), 95-101.
Haber, D. (2009). Gay aging. Gerontology E Geriatrics Education, $30(3), 267-280$.

Kimmel, D. (2014). Lesbian, gay, bisexual, and transgender aging concerns. Clinical Gerontologist, 37(1), 49-63.

MetLife Mature Market Institute \& the Lesbian and Gay Aging Issues Network of the American Society on Aging. (2010). Out and aging: The MetLife study of lesbian and gay baby boomers. Journal of GLBT Family Studies, 6(1), 40-57.

Ontario Ministry of Health and Long-Term Care (MOHLTC). (2012). Health equity impact assessment workbook. Retrieved from http://www.health.gov.on.ca/en/pro/ programs/heia/docs/workbook.pdf

Pietrus, M. (2013). Opening minds: Interim report. Calgary, AB: Mental Health Commission of Canada.

Porter, K. E., \& Krinsky, L. (2014). Do LGBT aging trainings effectuate positive change in mainstream elder service providers? Journal of Homosexuality, 61(1), 197-216.

Public Health Agency of Canada. (2013). What makes Canadians healthy or unhealthy? Retrieved from http://www.phac-aspc.gc.ca/ph-sp/determinants / determinants-eng.php

Stinchcombe, A., Smallbone, J., Wilson, K., \& Kortes-Miller, K. (2017). Healthcare and end-of-life needs of lesbian, gay, bisexual, and transgender (LGBT) older adults: A scoping review, Geriatrics, 2(1), 1-13. doi:10.3390/ geriatrics2010013

Wade, T. J., Bourgeault, I. L., \& Neiterman, E. (2015). The social dimensions of health and health care in Canada. North York, ON: Pearson Canada.

Witten, T. M. (2014). End of life, chronic illness, and transidentities. Journal of Social Work in End-of-Life \& Palliative Care, 10(1), 34-58. 